\title{
Stages of Synapse Development Defined by Dependence on F-Actin
}

\author{
Wandong Zhang and Deanna L. Benson \\ Fishberg Research Center for Neurobiology and Program in Cell Adhesion, The Mount Sinai School of Medicine, New \\ York, New York 10029
}

It has been widely speculated that actin plays a central role in CNS synapse assembly, but such a requirement for actin filaments (F-actin) has not yet been demonstrated experimentally. We used hippocampal neurons grown in culture and the actin depolymerizing agent, latrunculin $A$, to examine directly the relationship between $\mathrm{F}$-actin and synapse formation and maturation. During the first week in culture, actin depolymerization results in a near complete loss of synapses defined by synaptophysin-labeled vesicle clusters, synaptic vesicle recycling, and ultrastructure. Over the second week in culture, F-actin becomes increasingly stable, but actin depolymerization no longer disrupts basic synaptic structure. There is, however, a reduction in the number and size of synaptophysinlabeled clusters and in the size of vesicle clusters undergoing FM4-64 recycling, suggesting that synaptic vesicle anchoring remains partially dependent on F-actin. By $18 \mathrm{~d}$ in culture, synaptophysin clusters and synaptic vesicle recycling are largely resistant to F-actin depolymerization. The decrease in synapse dependence on F-actin correlates well with the acquisition and retention of presynaptic scaffolding proteins such as Bassoon and postsynaptic scaffolding proteins such as those of the postsynaptic density-95 family. Increased activity stabilizes F-actin and its associated proteins at synaptic sites, suggesting a correlation between active synapses, actin stability, and synapse stability. Our findings demonstrate that F-actin is essential for the development and maintenance of young synapses. Because F-actin is also highly regulatable, we propose that F-actin may be a principal target for stabilizing or destabilizing signals that ultimately result in synapse maintenance or elimination.

Key words: actin; presynaptic terminal; postsynaptic density; Bassoon; synaptophysin; tetanus toxin; PSD-95; cadherin; synapse adhesion; $\alpha$-internexin; dendritic spines
Synaptogenesis is most often presented as a hierarchy of recognition, adhesion, and protein targeting that begins with axonal guidance to the appropriate brain region and ends with neurotransmitter release opposite the appropriate cluster of neurotransmitter receptors and signaling molecules. However, the capacity for the continued acquisition, attrition, and modification of synapses throughout life is clearly recognized. It is certain that both stable and dynamic cytoskeletal elements are essential components of synaptogenesis, but there are a number of reasons to believe that actin in particular plays a key role. Actin is concentrated at developing presynaptic terminals (Dai and Peng, 1996; Bernstein et al., 1998) and is a major component of postsynaptic densities (Kelly and Cotman, 1978; Adam and Matus, 1996), where it anchors a population of postsynaptic receptors and signaling molecules opposite presynaptic terminals (Allison et al., 1998, 2000; Kim and Lisman, 1999). Significantly, actin reorganizes and concentrates at adhesion sites during formation of

\footnotetext{
Received Nov. 27, 2000; revised April 10, 2001; accepted May 1, 2001.

This research was supported by National Institutes of Health (NIH) U.S. Public Health Service Grant NS37731, National Science Foundation (NSF) Grant IBN9728003, and an Irma T. Hirschl Career Scientist Award. We thank Alice Elste for EM, Martin Valcin and Christina Nadar for excellent technical assistance, and Dr. David R. Colman and Dr. Craig C. Garner for antibodies. We are especially grateful to Dr. G. Withers, Dr. G. W. Huntley, Dr. C. C. Garner, and members of the Benson lab for critical comments and helpful suggestions. Some of the confocal laser scanning microscopy was performed at the Mount Sinai School of Medicine Microscopy Center, supported with funding from NIH shared instrumentation Grant 1 S10 RR0 9145-01 and NSF Major Research Instrumentation Grant DBI-9724504.

Correspondence should be addressed to Dr. Deanna L. Benson, Box 1065/ Neurobiology, The Mount Sinai School of Medicine, 1425 Madison Avenue, New York, NY 10029. E-mail: deanna.benson@mssm.edu.

Copyright (C) 2001 Society for Neuroscience 0270-6474/01/215169-13\$15.00/0
}

epithelial cell-cell junctions (Adams et al., 1996). A number of molecules have been proposed to adhere presynaptic and postsynaptic membranes together, including cadherins, integrins, neurexins and neuroligins, Narp, ephs and ephrins, and densin-180 (Apperson et al., 1996; Einheber et al., 1996; Fannon and Colman, 1996; Hsueh et al., 1998; Torres et al., 1998; O'Brien et al., 1999; Scheiffele et al., 2000). Of these, cadherins, integrins, and neuroligins have in common the capacity to anchor themselves to the actin cytoskeleton, suggesting that actin-anchored adhesion may be involved in the process of synaptogenesis (Zhang and Benson, 2000). Surprisingly little, however, is known about the requirements for F-actin during formation of the CNS synaptic junction.

In synaptic terminals, F-actin has been proposed to tether the reserve pool of synaptic vesicles to a region located distal to the vesicles docked at the presynaptic active zone (Hirokawa et al., 1989; Kelly, 1993; Pieribone et al., 1995; Kuromi and Kidokoro, 1998). In support of this, nerve terminals arising from young motor neurons, retinal ganglion cells, or hippocampal neurons require dynamic actin for continuous vesicle recycling as well as for short-term plasticity (Wang et al., 1996; Bernstein et al., 1998; Kuromi and Kidokoro, 1998; Kim and Lisman, 1999). Recent work suggests that the readily releasable pool may also be regulated by actin (Morales et al., 2000). The story at more mature terminals is less clear: synaptic vesicle localization, clustering, recycling, and release as well as paired-pulse facilitation, posttetani potentiation, and the induction of long-term potentiation (LTP) appear to be largely independent of actin assembly (Betz and Henkel, 1994; Job and Lagnado, 1998; Krucker et al., 2000). 
In fact, at mature neuromuscular junctions, presynaptic actin appears to intercalate between active zones where it might organize the terminal rather than regulate vesicle availability (Dunaevsky and Connor, 2000). Collectively these data suggest that the role of actin in presynaptic terminals may be changing over time.

Here we use high-resolution microscopy and the actin depolymerizing agent latrunculin A to address three questions. First, is F-actin required for assembly and maintenance of synapses? Second, how does activity, a principal driving force behind the maturation and sculpting of synaptic terminal arbors (Katz and Shatz, 1996), influence the relationship between F-actin and synapses? Third, what might contribute to time-dependent changes in the relationship between actin and synapses? Our findings indicate that F-actin is an essential component of developing synapses.

\section{MATERIALS AND METHODS}

Cultures and cytochemistry. Dissociated neuronal cultures were prepared from hippocampi of embryonic day 18 rats as described previously (Goslin and Banker, 1991; Benson and Cohen, 1996), plated at a density of 3600-7200 cells $/ \mathrm{cm}^{2}$, and maintained for up to 4 weeks in defined MEM containing N2.1 supplements.

F-actin was visualized using Oregon Green- or Texas Red-conjugated phalloidin (Molecular Probes, Eugene, OR). Synaptic vesicles were identified using antibodies against synaptophysin, a synaptic vesicle integral membrane protein [monoclonal (Boehringer Mannheim, Mannheim, Germany) and G95 (gift of Pietro DeCamilli, Yale University)]. An antibody against Bassoon (gift of Craig Garner, University of Alabama at Birmingham) was used to identify presynaptic cytomatrix (tom Dieck et al., 1998; Fenster et al., 2000; Zhai et al., 2000). An antibody directed against postsynaptic density-95 (PSD-95) (clone 6G6, Affinity BioReagents, Golden, $\mathrm{CO}$ ) was used as an excitatory postsynaptic density marker. It recognizes the closely related postsynaptic scaffolding proteins PSD-95/SAP90, PSD-93/chapsyn-110, and SAP97 (Sans et al., 2000). SAP97 can be presynaptic (Muller et al., 1995), but consistent with its early postnatal expression in hippocampus in vivo (Muller et al., 1995; Sans et al., 2000), it is either not present or not presynaptic in cultured hippocampal neurons. To localize the synaptic adhesion molecule $\mathrm{N}$-cadherin we used a polyclonal antibody made in guinea pig [abNCAD; gift of David R. Colman, Mount Sinai School of Medicine (Fannon and Colman, 1996)]. Anti- $\alpha$-internexin is a rabbit polyclonal antibody from Chemicon (Temecula, CA).

Neurons were fixed with $4 \%$ paraformaldehyde with $4 \%$ sucrose in PBS and permeabilized with $0.25 \%$ Triton X-100 except for localization of Bassoon and 6G6, where neurons were fixed and permeabilized in $-20^{\circ} \mathrm{C}$ methanol. Nonspecific labeling was blocked by preincubation in $5 \%$ normal goat serum in PBS, and neurons were incubated in primary antibodies at $4^{\circ} \mathrm{C}$ overnight. Secondary antibodies were conjugated to fluorescein or Texas Red (Vector Labs, Burlingame, CA). Fluorescent images were acquired using a confocal microscope (Zeiss LSM410 or Leica TCS SP, Thornwood, NY) and a 100×, 1.4 numerical aperture (NA) objective, a cooled charge-coupled device (Princeton Instruments, Trenton, NJ) mounted on a Nikon Diaphot, and a $60 \times, 1.4$ NA objective or a SPOT camera (Diagnostic Instruments) mounted on a Zeiss Axiophot microscope and a $40 \times 1.3$ NA objective.

Membrane labeling. For DiI labeling, neurons were fixed in paraformaldehyde and transferred into PBS. DiI dissolved in DMF $(0.5 \%)$ was
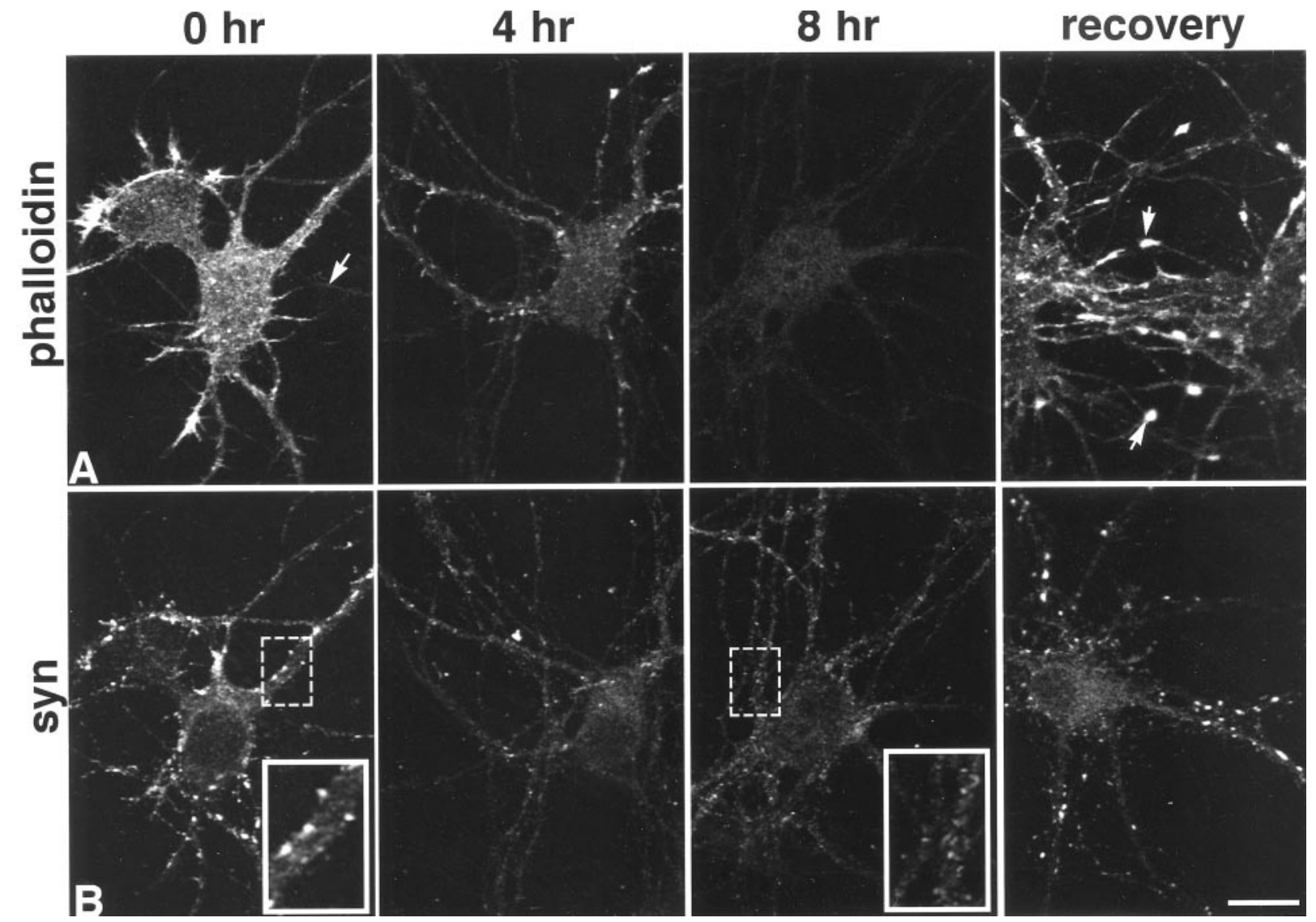

Figure 1. Time course of F-actin depolymerization and loss of synaptophysin (syn) clusters in 5-d-old cultured hippocampal neurons. Phalloidin labeling shows that latrunculin A depolymerizes most F-actin by $4 \mathrm{hr}$ and essentially all of it by $8 \mathrm{hr}(A$, arrow at 0 hr indicates axon). After incubation in fresh medium overnight, F-actin levels are similar to those seen at $0 \mathrm{hr}$, but growth cones become particularly enriched (arrows in $A$, recovery). Synaptophysin labeling $(B)$ over the same time course reveals a progressive loss of synaptic clusters along dendrites that is replaced by lightly labeled, small granules that extend through most processes (compare insets). After recovery, synaptophysin clusters are indistinguishable from those in control cultures. Scale bar, $20.2 \mu \mathrm{m}$; insets, $10.1 \mu \mathrm{m}$. 
Table 1. Effects of actin depolymerization on synaptophysin-labeled puncta

\begin{tabular}{|c|c|c|c|c|c|}
\hline \multirow{2}{*}{$\begin{array}{l}\text { Neuron age } \\
\text { (days in vitro) }\end{array}$} & \multicolumn{2}{|c|}{ Puncta $/ 100 \mu \mathrm{m}$} & \multicolumn{2}{|c|}{ Puncta area $\left(\mu \mathrm{m}^{2}\right)$} & \multirow{2}{*}{$\frac{\text { Intensity ( } \% \text { control) }}{\text { Post-LAT }}$} \\
\hline & $\mathrm{CON}$ & Post-LAT & $\mathrm{CON}$ & Post-LAT & \\
\hline $5-6$ & $31.7 \pm 3.5$ & $2.9 \pm 1.5^{*}$ & $0.35 \pm 0.03$ & $0.24 \pm 0.02 * *$ & $98 \pm 3.2$ \\
\hline $12-13$ & $96.8 \pm 7.2$ & $66 \pm 6.5^{* * *}$ & $0.49 \pm 0.01$ & $0.35 \pm 0.01 *$ & $90 \pm 4.5$ \\
\hline $18-20$ & $86.6 \pm 4.3$ & $71.9 \pm 7$ & $0.41 \pm 0.01$ & $0.48 \pm 0.01$ & $91 \pm 1.0$ \\
\hline
\end{tabular}

CON, Control; post-LAT, after latrunculin A. ${ }^{*} p<0.0001 ;{ }^{* *} p=0.036 ;{ }^{* * *} p=0.004$. Numbers are mean \pm SEM.

further diluted in PBS at 1:10,000 and incubated with neurons for $1 \mathrm{hr}$. After three washes in PBS, DiI was allowed to diffuse overnight (modified from Sattler et al., 2000). The technique completely labeled a small number of neurons.

Actin depolymerization. To depolymerize actin, latrunculin A (Molecular Probes) dissolved in ethanol or DMSO was added to cultures at 2.5 $\mu \mathrm{M}$ (final ethanol and DMSO concentrations, $0.1 \%$ ) for $4-8 \mathrm{hr}$ in 5- to 6-d-old cultures and for 10-24 hr in 12- to 20-d-old cultures (see Results). This treatment led to a reversible disruption of F-actin. To increase synaptic activity, neurons were incubated in conditioned media containing $25-75 \mathrm{~mm} \mathrm{KCl}$ for $5 \mathrm{~min}$. Osmolarity was maintained.

Vesicle recycling. Vesicle recycling in the presence and absence of tetanus toxin (TeNT) and latrunculin A was performed by modifying a protocol initially described by Verderio et al. (1999). Neurons on glass coverslips were placed in a chamber (Nicholson Precision Instruments) perfused with (in $\mathrm{mm}$ ): $124 \mathrm{NaCl}, 5 \mathrm{KCl}, 0.2 \mathrm{CaCl}_{2}, 1 \mathrm{MgCl}_{2}, 30$ dextrose, 25 HEPES, pH7.3 adjusted to $300 \mathrm{mOsm}$. They were exposed to $15 \mu \mathrm{M}$ FM4-64 dye (Molecular Probes) for $45 \mathrm{sec}$ in high $\left[\mathrm{K}^{+}\right]$(same buffer with $90 \mathrm{mmKCl}, 39 \mathrm{~mm} \mathrm{NaCl}$ ), washed for $10 \mathrm{~min}$, then imaged using a Nikon Diaphot (see above). Neurons were then exposed to four alternating cycles of high $\left[\mathrm{K}^{+}\right]$and imaging media to release the dye, then imaged again. For latrunculin A treatments, neurons were exposed to $2.5 \mu \mathrm{M}$ latrunculin A for 3-6 hr (6- to 7-d-old neurons) or for 20-24 hr (13- to 19-d-old neurons), washed, and then tested for vesicle recycling. For TeNT treatment, 5- to 7-d-old neurons were exposed to $10 \mathrm{~nm}$ TeNT (Alomone Labs, Jerusalem, Israel) for $5 \mathrm{~min}$ in the presence of high $\left[\mathrm{K}^{+}\right]$, washed, and then incubated at $37^{\circ} \mathrm{C}$ for $2-6 \mathrm{hr}$ in culture medium (TeNT alone) or 3-6 hr in culture medium with $2.5 \mu \mathrm{M}$ latrunculin A (TeNT + latrunculin A), after which they were tested for vesicle recycling. Two hours are sufficient to cleave synaptobrevin/vesicleassociated membrane protein 2 (VAMP2) (Verderio et al., 1999). Larger fluorescent clusters on somata and dendrites that can be destained are synaptic (Ryan et al., 1993) and sensitive to TeNT (Verderio et al., 1999), whereas smaller axonal spots that can be destained are not synaptic and are insensitive to TeNT (Verderio et al., 1999). Dendrites and axons were identified using differential interference contrast optics. Dendrites were identified as tapering processes that could be readily traced to their points of origin on the cell body, whereas axons were identified by their thin and undiminishing diameters in regions located at some distance from cell bodies and dendrites. Because neurons are plated at low density, relatively large spaces are covered only by axonal networks.

Electron microscopy. For electron microscopy, control and latrunculin A-treated cultures (three different cultures for each age) were fixed in $2.5 \%$ glutaraldehyde diluted in $\mathrm{N} 2.1$ at $37^{\circ} \mathrm{C}$ for $10 \mathrm{~min}$, then $2.5 \%$ glutaraldehyde in $0.1 \mathrm{M} \mathrm{PO}_{4}$ buffer $(\mathrm{PB})$ at $37^{\circ} \mathrm{C}$ for $30 \mathrm{~min}$. After cultures were washed in $\mathrm{PB}$, they were fixed in $1.5 \%$ osmium tetroxide in $\mathrm{PB}$ for $30 \mathrm{~min}$ at room temperature, washed in distilled water, dehydrated in 50 and $70 \%$ ethanol, then stained for $30 \mathrm{~min}$ in $2 \%$ uranyl acetate in $70 \%$ ethanol, after which they were further dehydrated in increasing concentrations of ethanol. Cultures were embedded in Epon. Thin sections were cut on a Reichert-Jung ultramicrotome (Peabody, MA), then stained with 5\% uranyl acetate for $10 \mathrm{~min}$ and Reynolds' lead citrate for $10 \mathrm{~min}$. Sections were viewed on a Jeol 1200 EX electron microscope and photographed using an Advanced Microscopic Techniques digital camera (Danvers, MA) at magnifications from 10,000 to $20,000 \times$. Synapses were identified using standard morphological criteria (Peters et al., 1991).

Quantification. Measurements of intensity and puncta or cluster area were determined as described (Bozdagi et al., 2000). Briefly, images were acquired using the same brightness and contrast settings, imported into the public-domain NIH Image program v1.61 or IP Lab Spectrum (Vienna, VA), and a thesholding function (density slice/segmentation) was used to select only labeled regions (for distributed labeling) or hot spots (for clustered labeling). Single-image digital deconvolution (Mic- rotome) was applied to images from FM4-64 labeling to remove fluorescent haze (VayTec, Fairfield, IA). For clusters, threshold levels were determined by the user to maximize the number of individual puncta while minimizing the numbers of fused puncta, then maintained for each data set. At least two different cultures and at least 100 puncta per culture were counted (5- to 6-d-old cultures; older cultures had several thousand puncta). Area and intensity (average intensity per puncta or labeled region on a scale of $0-255$ intensity units per pixel) data were exported to Excel, and differences between conditions were compared using a Student's $t$ test (two comparisons) or ANOVA and Fisher's post hoc test (three or more comparisons). Numbers of boutons were counted on dendritic lengths that were measured using IP labs or Photoshop.

\section{RESULTS}

\section{F-actin is required to maintain young synapses}

Hippocampal neurons grown in culture develop structural and functional synapses similar to those that develop in vivo (Segal, 1983; Bartlett and Banker, 1984; Fletcher et al., 1991). Synaptogenesis begins on the third day in culture and reaches a plateau by the third week. Thus, during the first week, most of the synapses are newly formed.

It has been established in relatively mature cultured hippocampal neurons $(>21 \mathrm{~d})$ that postsynaptic molecules are differentially dependent on the integrity of the actin cytoskeleton for their colocalization with presynaptic markers (Allison et al., 1998, 2000). Here we examine whether the synaptic junction itself is dependent on F-actin and whether its relationship with F-actin changes over time. To do this F-actin was depolymerized using the G-actin binding drug latrunculin A, and its effect on synapses was assessed using four different methods: synaptic vesicle clustering, synaptic vesicle recycling, electron microscopy, and the accumulation of synaptic proteins.

In 5- to 6-d-old cultures, F-actin, detected by fluorophoretagged phalloidin, is present in all neurons and throughout all neuronal compartments, but dendrites contain more than axons (Fig. $1 A$, arrow), and growth cones are particularly enriched (Fig. 1A) (Goslin et al., 1989). Addition of $2.5 \mu \mathrm{M}$ latrunculin A results in a progressive loss of $\mathrm{F}$-actin beginning after $1 \mathrm{hr}$ and continuing over the course of $4-8 \mathrm{hr}$, after which F-actin is completely depolymerized (Fig. 1A). When treated cultures are allowed to recover in fresh media overnight $(\sim 12 \mathrm{hr})$, F-actin repolymerizes in somata and neurites and appears super-enriched in growth cones (Fig. 1A).

The acquisition of synaptic vesicles appears to be among the first steps in synapse formation. When neurons are cultured according to methods developed by Banker and colleagues (Goslin and Banker, 1991), synapse formation correlates strongly with the acquisition of focal accumulations of labeling for synaptic vesicle proteins such as synaptophysin along cell bodies and dendrites (Fletcher et al., 1991). Synaptophysin-labeled clusters thus provide an accurate estimate of presynaptic terminals that are easy to quantify at the light microscopic level (Hiscock et al., 2000). F-actin depolymerization is accompanied by the loss of 
nearly all detectable synaptophysin clusters (Table 1, Fig. 1B), and the few remaining puncta are $30 \%$ smaller (Table 1), suggesting that most clusters of synaptic vesicles are tethered by F-actin. Clustered synaptophysin labeling is replaced by light, granular labeling that extends along processes for considerable distances and probably corresponds to vesicles redistributed from synaptic boutons (Fig. $1 B$, insets). After recovery for $24 \mathrm{hr}$ in fresh media, synaptophysin cluster number, size, and intensity return to normal values and are indistinguishable from untreated controls (Fig. $1 B$ ) ( $t$ test; $p=0.63, p=0.52$, $p=0.75$, respectively).

Recent work suggests that presynaptic boutons capable of recycling may not be associated with obvious clusters of synaptic vesicles (Ahmari et al., 2000) and ultrastructural examination of developing synapses indicates that some synaptic specializations have very small vesicle clusters (Fiala et al., 1998), perhaps too small to be detected by conventional light microscopic immunocytochemical localization methods. Activity-dependent uptake and release of styryl dyes can be used to pinpoint sites of active synaptic vesicle recycling and are often used to identify synapses (Ryan et al., 1993; Betz and Henkel, 1994; Friedman et al., 2000; McAllister and Stevens, 2000). However, regions of axons that are not participating in synapses can also recycle vesicles (Kraszewski et al., 1995; Verderio et al., 1999; Zakharenko et al., 1999). Nonsynaptic axonal recycling sites can be distinguished from synaptic sites in that they are smaller, are not particularly associated with somata or dendrites (Kraszewski et al., 1995), and are insensitive to treatment with TeNT (Verderio et al., 1999), which cleaves the vesicle SNARE (soluble $N$-ethylmaleimide-sensitive factor attachment protein receptor) protein synaptobrevin/ VAMP2 and renders presynaptic terminals incapable of recycling (Schiavo et al., 1992). When control 5- to 6-d-old neurons are stimulated with high $\left[\mathrm{K}^{+}\right]$for $45 \mathrm{sec}$ in the presence of FM4-64, most of the larger dye-loaded synaptic vesicles are clustered along somata and dendrites (Fig. 2A), whereas smaller puncta are observed along axons. Stimulation in the absence of the dye releases most of the somatodendritic clusters $(53 \pm 8 \%)$ and some of the axonal labeling as well. In latrunculin A-treated neurons (Fig. 2B), loaded vesicles are significantly smaller (Fig. 2E) and are mostly associated with axons (Fig. $2 B$ ), suggestive of the nonsynaptic pool. This identification was verified, in that the size of labeled vesicles from preparations treated with latrunculin A was quantitatively indistinguishable (Fig. 2E) from the vesicle size in neurons treated with TeNT alone (Fig. $2 C$ ) or latrunculin A and TeNT (Fig. 2D). Together these data indicate that actin depolymerization blocks synaptic activity in 5- to 6-d-old neurons by disrupting synaptic vesicle release at presynaptic boutons.

To determine whether F-actin depolymerization notably altered synapse morphology, control and latrunculin A-treated neurons were examined qualitatively at the ultrastructural level. Synapses were conservatively identified by the presence of more than three docked vesicles and aligned and thickened presynaptic and postsynaptic membranes with intervening dense material. Along somata and dendrites, synapses are relatively numerous and easily identified in control 6-d-old neurons (Fig. 3A-C), but in neurons treated with latrunculin A (Fig. $3 D-G)$, there are no morphologically identifiable synapses. Rare structures could be found resembling synapses, but they lacked critical elements (Fig. 3G). Processes in treated cultures have noticeable increases in vesicles of all kinds: small clear, clathrin-coated, and large dense-core, as well as tubulovesicular structures (Fig. $3 E, F$ ), suggesting that synaptic components may be endocytosed or they may diffuse or

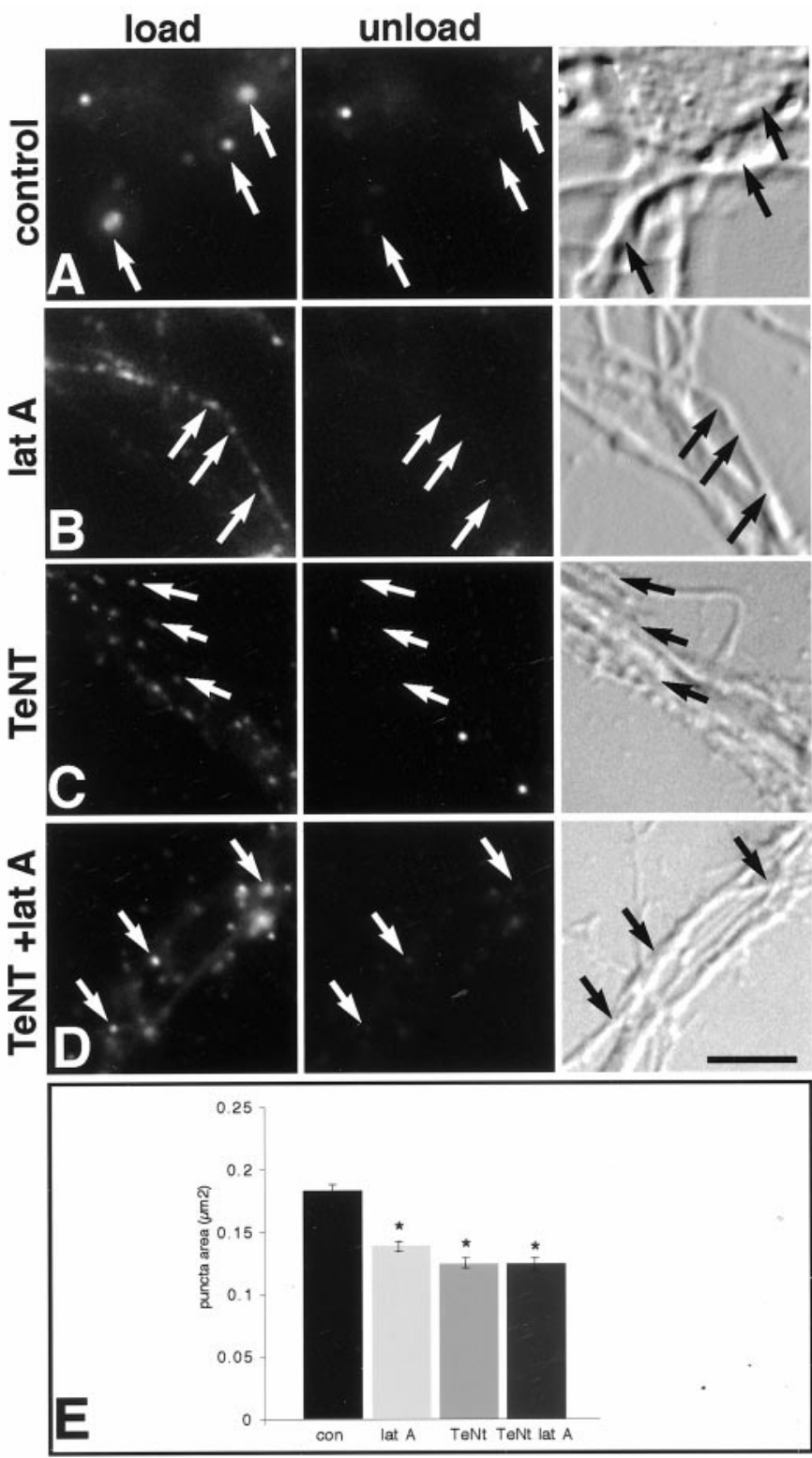

Figure 2. Actin depolymerization disrupts synaptic vesicle recycling in presynaptic boutons, whereas recycling in axons is unperturbed. Fluorescent (left and middle panels) and bright-field images (right panels) show activity-dependent recycling indicated by activity-dependent FM4-64 dye uptake in left panels (load), and subsequent activity-induced destaining in middle panels (unload). Arrows indicate recycling sites. Most recycling sites in control neurons are larger and associated with somata and dendrites $(A)$, whereas in latrunculin $\mathrm{A}$ (lat $A)$-treated neurons they are smaller and mostly associated with axons $(B)$. After treatment with TeNT alone $(C)$ or TeNT and latrunculin $\mathrm{A}(D, T e N T+$ lat $A)$, all of the cycling boutons are small and mostly associated with axons that often fasciculate together $(C, D)$. E, Quantitative analysis of the area of recycling puncta shows control puncta to be significantly larger than any of the treatment groups, which are not significantly different from one another. An asterisk indicates a significant difference from control (ANOVA, $p<0.0001$; Scheffe's post hoc analysis). Scale bar, $7.9 \mu \mathrm{m}$.

are trafficked away from the synapse in response to actin depolymerization. Basic ultrastructure is otherwise unperturbed (Fig. $3 D$ ). These data indicate that maintenance of a morphologically identifiable synapse in 5- to 6-d-old neurons is dependent on polymerized actin. 

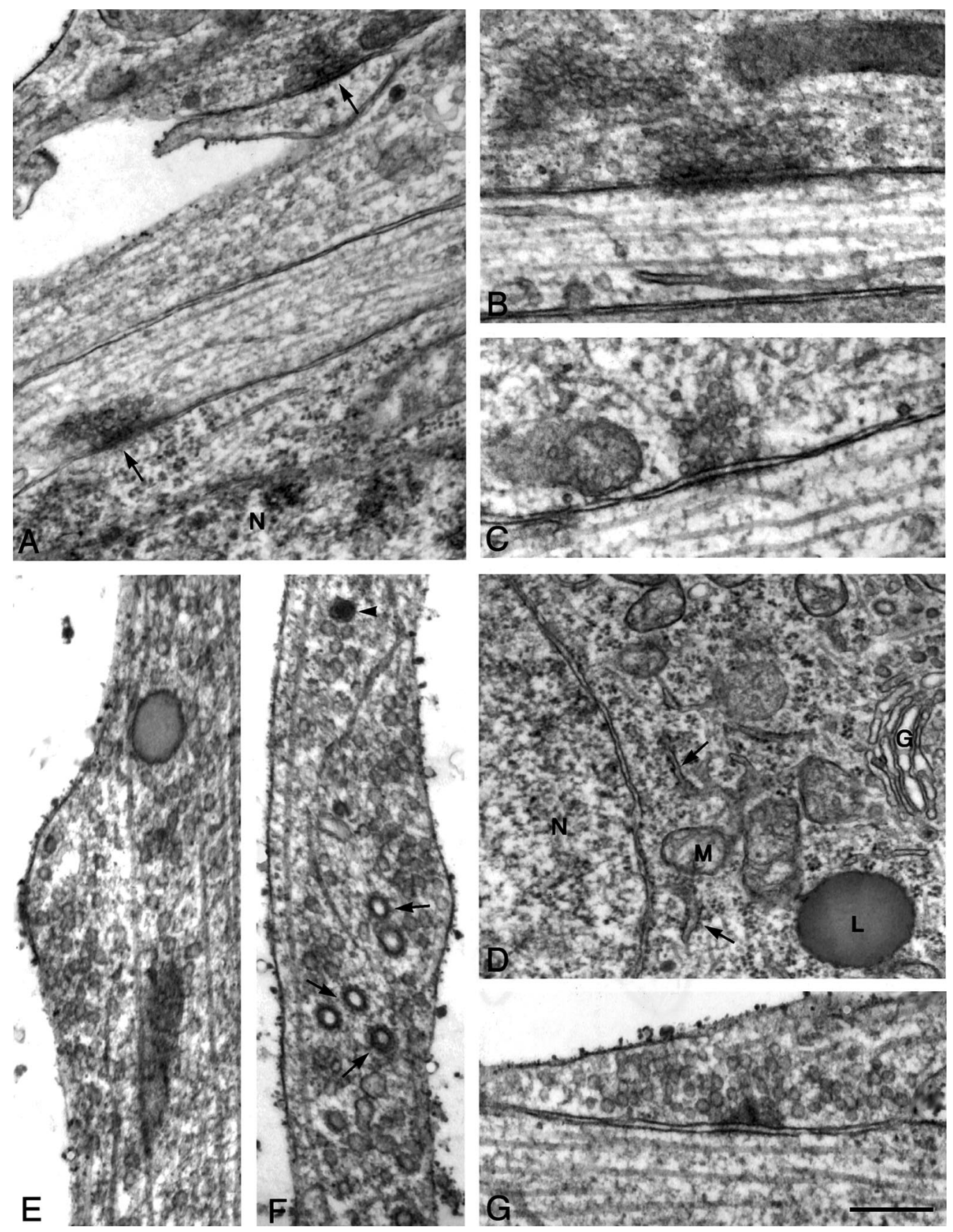

Figure 3. Actin depolymerization results in loss of synaptic ultrastructure. Electron photomicrographs of 6-d-old neurons from control ( $A-C)$ and latrunculin A-treated $(D-G)$ cultures. In untreated 6-d-old cultures, synapses are relatively common $(A$, arrows $)$ and range from mature morphology having a large number of vesicles and a well formed postsynaptic density $(B)$ to those having much smaller numbers of vesicles and only slight postsynaptic densities $(C)$. After latrunculin A treatment, neurons look surprisingly normal as demonstrated by the clearly defined nuclear membrane, endoplasmic reticulum (arrows), and Golgi apparatus in a cell soma $(D)$. Processes have increased numbers of small vesicles $(E)$, clathrin-coated vesicles (arrows), tubulovesicular bodies, and large dense-core vesicles $(F$, arrowhead). Rare structures can be seen resembling synapses $(G)$, but in the example shown the presynaptic density is unusually broad, cleft material is sparse, and synaptic vesicles are not apposed to the active zone. Scale bar: $A, D$, 500 $\mathrm{nm} ; B, C, E-G, 250 \mathrm{~nm}$. $N$, Nucleus; $G$, Golgi; $M$, mitochondria; $L$, lysosome.

\section{Synapses become independent of increasingly stable F-actin}

Neurons that are 10-13 d old require an exposure to latrunculin A that is three times longer $(16-20 \mathrm{hr})$ than that required to depolymerize F-actin in 5- to 6-d-old neurons (Fig. 4A,C). Because latrunculin $\mathrm{A}$ acts by binding to $\mathrm{G}$-actin, we interpret this to mean that F-actin has become exceedingly stable. The conditions required to depolymerize $\mathrm{F}$-actin at this age are similar to what has been reported for 3-week-old cultures (Allison et al., 1998).
In stark contrast to 5- to 6-d-old neurons, many synaptophysinlabeled clusters remain in latrunculin A-treated 10- to 13-d-old neurons (Fig. $4 B, D$ ). However, quantitative analysis reveals that $31 \%$ of the vesicle clusters are lost and those that remain are $29 \%$ smaller than in controls (Table 1). These data indicate that only one-third of the clusters are completely dependent on F-actin, whereas most become partially independent of F-actin anchoring. This is consistent with evidence suggesting that the synaptic vesicle reserve pool is linked to the actin cytoskeleton via synapsin I 

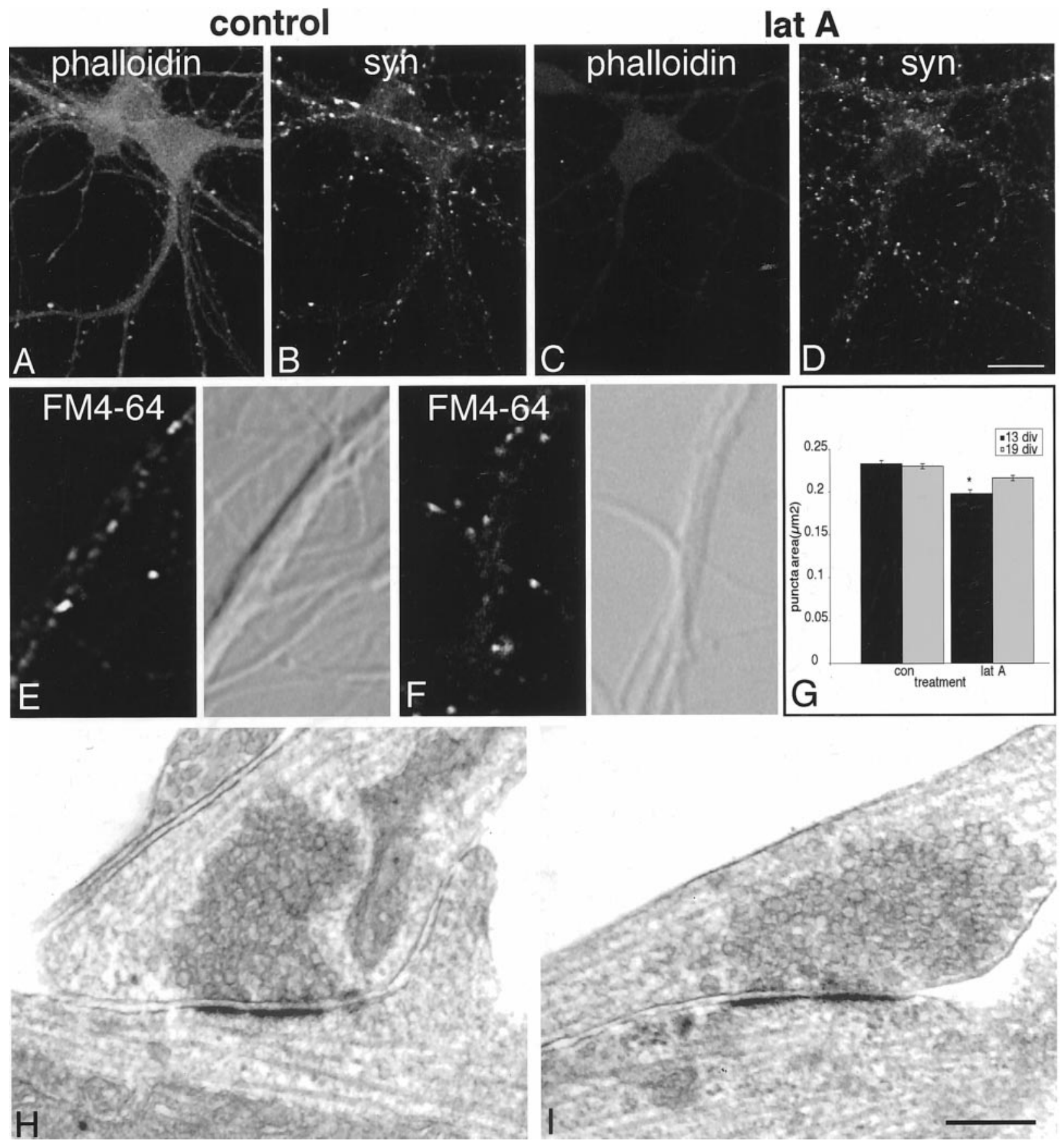

Figure 4. In 12-d-old neurons, the effects of actin depolymerization are modest. Phalloidin-labeled F-actin $(A)$ requires $16-20$ hr of incubation in latrunculin A (lat $A)$ to depolymerize $(C)$. Synaptophysin (syn) labeling remains largely intact $(B$ vs $D)$, but individual puncta are reduced in size and number (Table 1). In both control $(E)$ and latrunculin A-treated $(F)$ 12-d-old neurons, FM4-64 uptake (left panels) is largely restricted to clusters on somata and dendrites (compare with differential interference contrast images in right panels). Cluster area is slightly but significantly reduced in size ( $G$, the asterisk indicates a significant difference from control, $p<0.0001)$. Electron microscopy of 12-d-old neurons reveals that synapses in control cultures cover a broad range of maturity $(H)$ and are not distinguishably different in latrunculin A-treated cultures $(I)$. Scale bar: $A-D, 26.9 \mu \mathrm{m} ; E-H, 250 \mathrm{~nm}$.

(Pieribone et al., 1995) but also suggests that most synaptic vesicles have developed an alternative or additional link with the synapse.

In control 12- to 13-d-old neurons, vesicle clusters that undergo FM4-64 recycling are larger than in 5- to 6-d-old neurons and are mostly restricted to soma and dendrites $(4 E, F)$. After actin depolymerization, puncta size decreases significantly, but to a much lesser extent than that observed at 5-6 days in vitro (Fig. 4G).

Ultrastructural observations show few differences between control and latrunculin A treated 12-d-old neurons. In both conditions there are large numbers of synapses on somata and dendrites. Latrunculin A-treated dendrites appeared to have more clathrin-coated vesicles (data not shown), but there are no overt morphological differences between synapses in the two groups (Fig. 4, compare $H, I$ ). These data indicate that over the course of 1 week, while F-actin itself is becoming increasingly stable, the basic morphological structure of a number of synapses becomes largely independent of F-actin. However, in light of the 


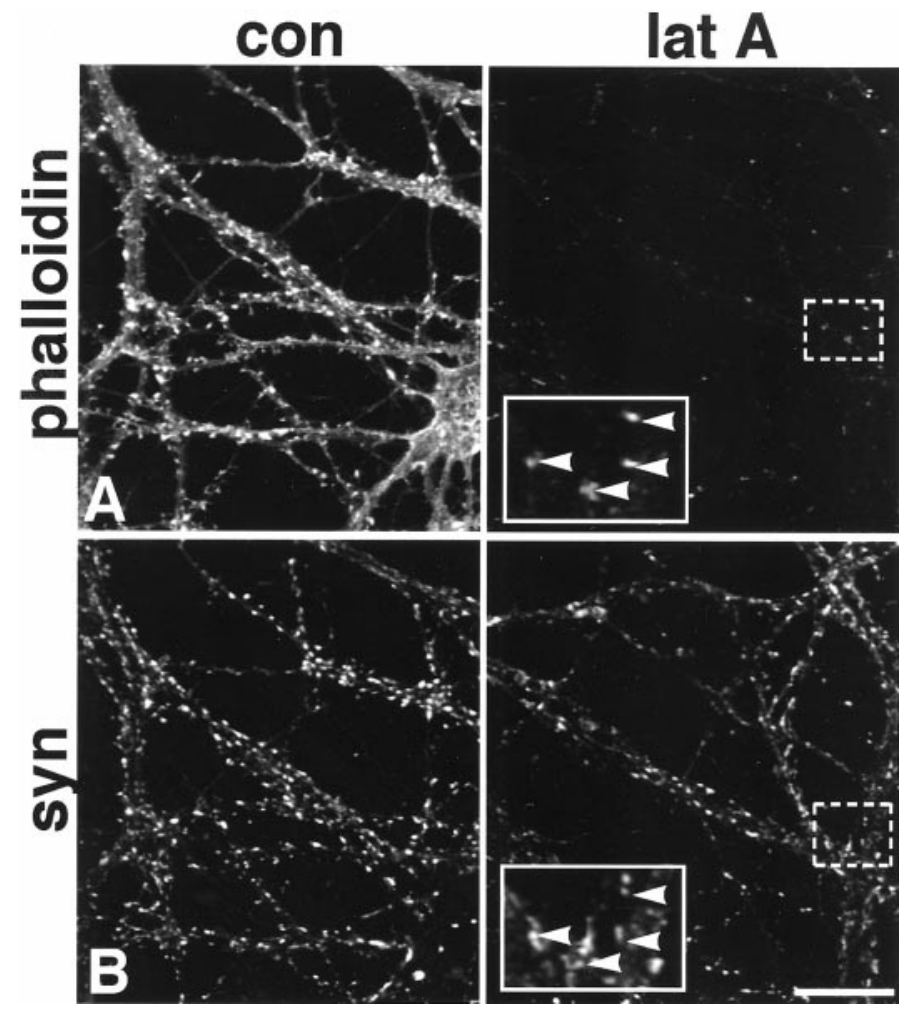

Figure 5. In 20-d-old neurons, some synaptic F-actin is exceedingly stable. Most F-actin is depolymerized in $24 \mathrm{hr}(A)$. However, even at 24 $\mathrm{hr}$, some F-actin clusters remain $(A)$. Synaptophysin $(s y n)$ labeling $(B)$ of the same neurons shown in $A$ is unaltered by the treatment. Boxed regions are shown at higher magnification in insets and illustrate that many of the most stable F-actin puncta are codistributed with synaptophysin puncta (arrowheads).con, Control; lat A, latrunculin A. Scale bar, $26.9 \mu \mathrm{m}$; insets, $10.8 \mu \mathrm{m}$.

decreased size of vesicle clusters that we detected by light microscopy, it is likely that three-dimensional reconstruction of synapses will reveal some interesting distinctions between the two groups, and this will be the subject of future studies.

In 18- to 20-d-old neurons, nearly all F-actin can be depolymerized over $24 \mathrm{hr}$, but a very small number of F-actin puncta remain resistant to latrunculin $\mathrm{A}$ (Fig. $5 \mathrm{~A}$ ). It is possible that the drug may not be accessible at some sites, but it is more likely that this small population of F-actin sites is extremely stable. Increased latrunculin A concentrations (from 2.5 to $10 \mu \mathrm{M}$ ) or increased incubations times (up to $48 \mathrm{hr}$ ), or both, did not noticeably alter the small number of stable puncta. Because the vast majority of the F-actin is depolymerized in the neurons, it appears that F-actin at a small number of sites is sufficiently protected by capping and side-binding proteins (Fowler, 1997) such that turnover is extremely slow. Interestingly, many of these stable sites were associated with synaptophysin clusters (Fig. $5 A, B$, insets).

Neurons that are 18-20 d old display a high degree of presynaptic stability in the face of actin depolymerization. Numbers of synaptophysin puncta were identical in the control and treated cultures, and punctal area was not significantly different, suggesting that the synaptic vesicle reserve pool as well as the releasable pool is not anchored by F-actin (Table 1, Fig. 5). Consistent with this idea, the size of vesicle clusters undergoing FM4-64 recycling did not change significantly when actin was depolymerized (Fig. 4G). These results are consistent with reports which indicate that some presynaptic and postsynaptic markers remain apposed after latrunculin A treatment in 3-week-old neurons (Allison et al., 1998, 2000).

\section{Increased neuronal activity can redistribute and stabilize synaptic F-actin}

Several reports show that activity can modulate actin (Bonfoco et al., 1996; Halpain et al., 1998; Furuyashiki et al., 1999; Wong et al., 2000), so we asked whether the small number of stable F-actin sites might be the result of recent synaptic activity. To investigate this link, we stimulated 17-d-old neurons with $75 \mathrm{~mm} \mathrm{KCl}$ before incubation in latrunculin A for $24 \mathrm{hr}$. Relative to unstimulated neurons, there is a $49 \%$ increase in the number of F-actin enriched synaptic puncta that are resistant to actin depolymerization (Fig. 6, $C$ vs $D$, and $G$ vs $H)(p=0.03)$. When neurons were fixed immediately after $\mathrm{KCl}$ stimulation, the Texas Red phalloidin intensity levels rose by $23 \%$ beneath the plasmalemma and in spines relative to unstimulated neurons (Fig. 6, $A$ vs $B)(p<$ 0.0001 ). Synaptophysin clusters also broaden (by $40 \%$ ), consistent with previous reports (Tanaka et al., 2000), and are likely to be caused by massive vesicle fusion with the presynaptic membrane (Fig. 6, $E$ vs $F$ ). The rapid, activity-triggered appearance of F-actin in plasmalemma and spines is similar to what has been described for the actin binding protein cortactin (Naisbitt et al., 1999). These data indicate that activity can trigger a rapid and selective polymerization or translocation, or both, of F-actin in neurons, and over a longer term (at least $24 \mathrm{hr}$ ), stabilization of F-actin at synaptophysin-enriched sites.

\section{Nascent presynaptic cytomatrix, cadherin-based adhesion, and postsynaptic markers are F-actin dependent at young synapses}

Our results indicate that synapses pass through at least two stages of development: one that is completely F-actin dependent and the other that is largely F-actin independent. This transition correlates with the clustering of a number of proteins at synapses (Benson and Tanaka, 1998; Rao et al., 1998; Zhai et al., 2000), and it is likely that the ensuing network of protein-protein interactions is what transforms the synapse into a more stable, actin-independent structure. We therefore examined the temporal acquisition of a subset of synaptic proteins representing distinct synaptic compartments-presynaptic cytomatrix (Bassoon), intermembrane adhesion (N-cadherin), and postsynaptic scaffold (PSD-95 family) - and determined their resistance to actin depolymerization over time (see Materials and Methods). In 5- to 6-d-old cultures, most synaptophysin clusters colocalize with smaller Bassoon puncta (Fig. 7A,B) (Zhai et al., 2000). Some very small synaptophysin puncta lack Bassoon (arrow) and perhaps correspond to newly formed synapses or to synapse components in transit (Ahmari et al., 2000; Friedman et al., 2000). N-cadherin is localized principally in larger clusters (Fig. 7D) that are synaptic (Fannon and Colman, 1996; Benson and Tanaka, 1998). In neurons where it can be detected, labeling for the PSD-95 family is punctate in somata and dendrites, but the puncta are small and faint, and more than half are not apposed to synaptophysin puncta (Fig. 7F, G, Table 2) (Rao et al., 1998).

After F-actin depolymerization, Bassoon clusters are nearly eliminated (Fig. 7C). N-cadherin clusters are completely lost (Fig. $7 E$ ). PSD-95 puncta are reduced in number and many appear within somata (Fig. 7H, Table 2). Together these data are consistent with the loss of morphologically identifiable synapses observed at the ultrastructural level after latrunculin A treatment, but they do not rule out the possibility that low levels of certain 

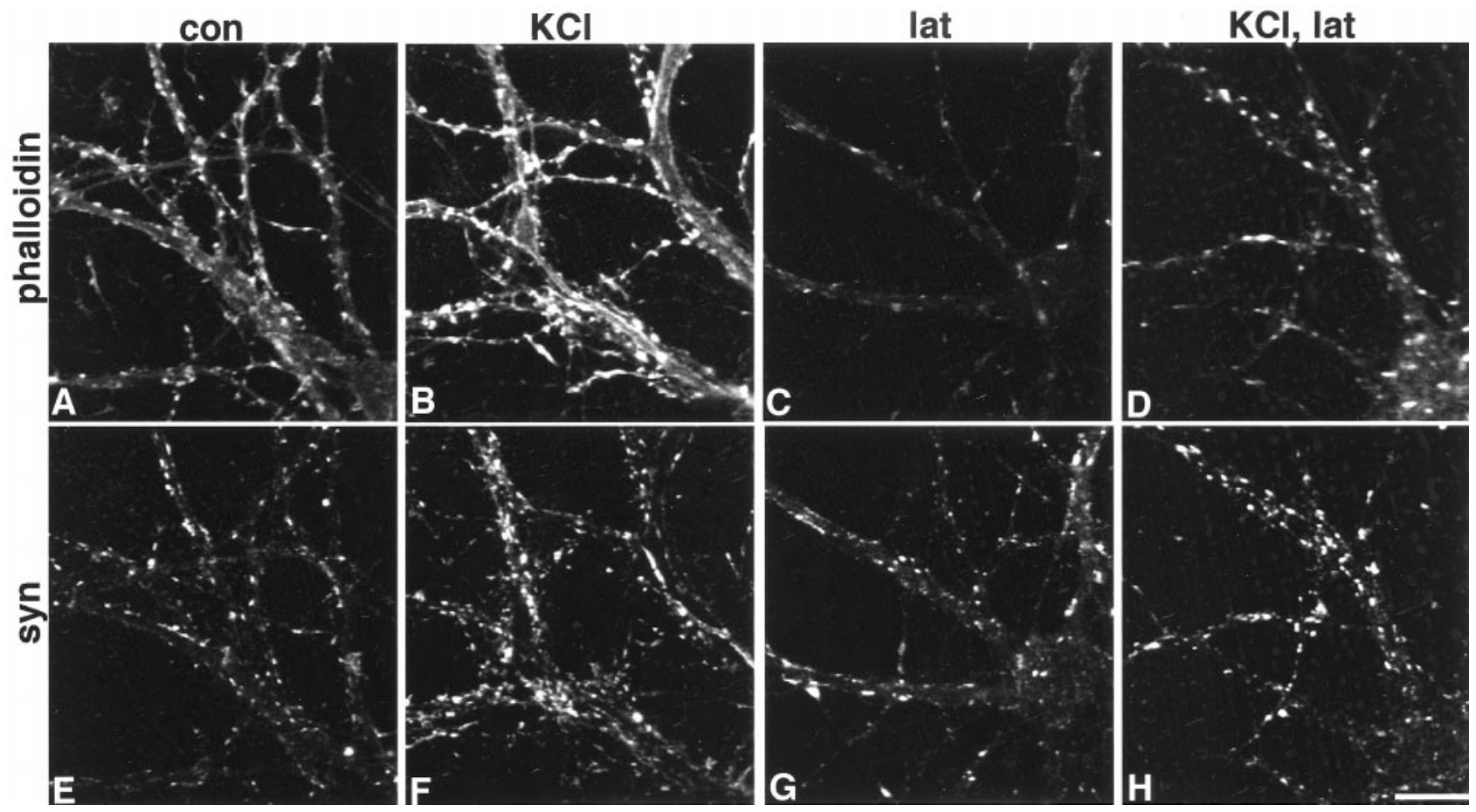

Figure 6. Activity can reorganize and stabilize F-actin. In 17-d-old neurons, 5 min exposure to $75 \mathrm{~mm} \mathrm{KCl}$ results in an increase in phalloidin-labeled F-actin in the cortex and dendritic protrusions [control $(A$, con $)$ vs stimulated $(B)$ ], and intensity of synaptophysin (syn)-labeled puncta appears to increase and spread slightly in the same neurons [control $(E)$ vs stimulated $(F)$ ]. When neurons incubated in latrunculin A $($ lat $)$ for 24 hr $(C, G)$ are compared with those that were first stimulated for $5 \mathrm{~min}$ with $75 \mathrm{~mm} \mathrm{KCl}(D, H)$, there are more phalloidin-labeled F-actin puncta $(D$ vs $C)$ that codistribute with synaptophysin-labeled puncta $(G, H)$ (compare $C$ and $G$ with $D$ and $H$ ). Scale bar, $20.2 \mu \mathrm{m}$.

proteins may be retained at synaptic sites to mark them for reinnervation.

\section{Retention of Bassoon and PSD-95 correlates with acquisition of F-actin-resistant synaptic puncta}

In 10- to 13-d-old neurons, Bassoon puncta are larger, more intensely labeled, and more numerous than in younger neurons (Fig. 8A, Table 2). N-cadherin puncta are also larger, brighter, and more numerous (Fig. $8 C$ ). By this time PSD-95 can be detected in all neurons, and the numbers of puncta within each neuron are dramatically increased (Fig. $8 F$ ). Most PSD-95 puncta codistribute with synaptophysin, but extrasynaptic puncta are seen (Fig. 8E,F, Table 2).

After latrunculin A treatment in 10- to 13-d-old neurons, Bassoon labeling is diminished in parallel with what is observed for synaptophysin $(30 \%$ decrease in punctal area and $27 \%$ decrease in punctal numbers) (Fig. $8 B$, Table 2). The percentage of PSD-95 puncta associated with synaptophysin-labeled sites declines by $17 \%$ (compared with control) (Fig. 8, $E$ and $F$ vs $G$ and $H$ ), whereas numbers of nonsynaptic PSD-95 puncta increase slightly in dendrites $(p=0.08)$ and significantly in somata $(p<$ 0.008 ) (Fig. $8, E$ and $F$ vs $G$ and $H$, Table 2). However, the increase in nonsynaptic puncta does not account entirely for the decline in synaptic puncta in that the total numbers of puncta are significantly diminished by $32 \%( \pm 7 \% ; p<0.004)$ in the treated neurons. N-cadherin clusters remain completely dependent on F-actin (Fig. 8D). Thus, elements of presynaptic cytomatrix along with synaptic vesicles at the majority of sites have become partially independent of F-actin for their localization, whereas approximately half the postsynaptic clusters of PSD-95 remain dependent on F-actin for their localization at sites of presynaptic vesicle clusters. Most interestingly, $\mathrm{N}$-cadherin-based clustering and adhesion appear to be dispensable for maintaining synapse morphology at a number of sites.

Membrane protrusions revealed by DiI labeling remain in the absence of F-actin but appear more pointed and filopodia-like (Fig. 8, $K$ vs $L$ ) (Allison et al., 2000; Sattler et al., 2000). Interestingly, immunoreactivity for $\alpha$-internexin, an intermediate filament protein, remains at the bases of the pointed structures (Fig. $8, M$ vs $N$ ), suggesting a potential supportive element for the membranes that appear to remain engaged in a synaptic contact.

\section{Molecular constituents of mature synapses are largely independent of F-actin}

By $18 \mathrm{~d}$ in culture, Bassoon labeling, like that for synaptophysin, is undisturbed by latrunculin A treatment (Fig. 8, I vs $J$ ). PSD-95 remains coclustered with synaptophysin, as has been described previously (Allison et al., 2000). Only N-cadherin clusters are largely lost (data not shown), although a small number can be found at sites having stable, latrunculin A-resistant F-actin puncta (Fig. 5).

Our results, which are summarized in Figure 9, suggest that synapses progress through discrete stages over a protracted time period. When new synapses form, synaptic molecules are tethered to the actin cytoskeleton via actin binding proteins. At this stage, disruption of the F-actin cytoskeleton results in disassembly of synapse structure. At an intermediate stage (a juvenile synapse), some synaptic molecules remain tethered only to actin, whereas others are also linked to scaffold proteins that are beginning to form networks on both sides of the synapse. At relatively mature synapses, a few molecules remain tethered only to actin, but most have also attached to an elaborate intracellular and extracellular matrix via protein-protein interactions. Disassembly at this stage must be an active process that severs bonds and probably includes 

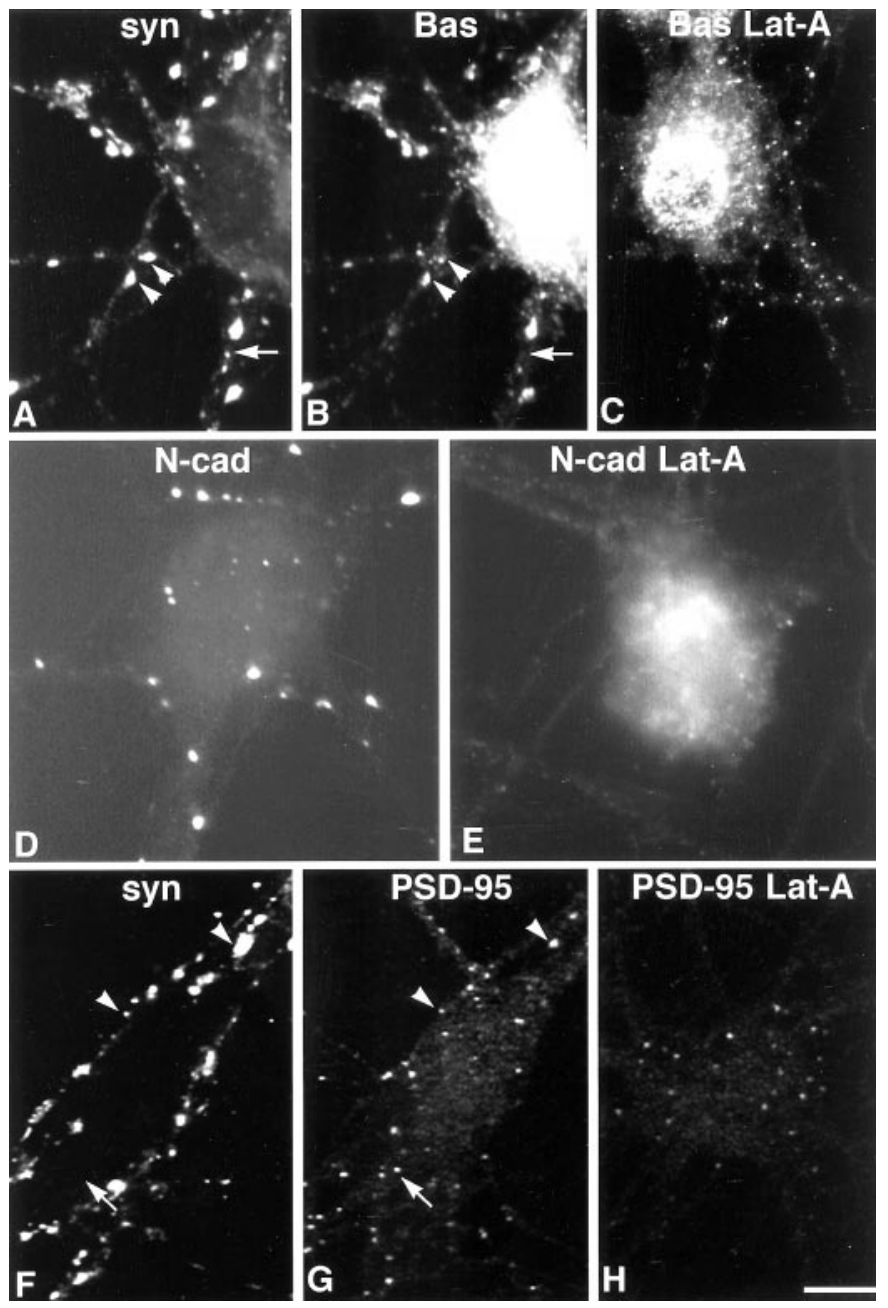

Figure 7. In 6-d-old neurons, the distribution of synaptic proteins is disrupted by latrunculin A. Bassoon (Bas) labeling $(B)$ mostly codistributes with synaptophysin $(A, s y n)$ in control cultures $(A, B$, arrowheads $)$, although small synaptophysin puncta sometimes lack detectable Bassoon labeling $(A, B$, arrow). Like synaptophysin, clusters of Bassoon labeling are greatly diminished after actin depolymerization $(C)$. Very small Bassoon-labeled puncta remain, perhaps denoting sites of synapse loss or the vesicles seen in processes after depolymerization. Clusters of synaptic $\mathrm{N}$-cadherin $(N$-cad) labeling $(D)$ are lost after exposure to latrunculin A $(E$, Lat- $A)$. Synaptophysin $(F)$ and PSD-95 $(G)$ are partially codistributed at this age (arrowheads), but a number of PSD-95 puncta are synaptophysin negative $(F, G$, arrow). After latrunculin A exposure, most PSD-95labeled puncta are found within cell somata $(H)$. Scale bar, $11.3 \mu \mathrm{m}$.

protease activation. Strong activity can greatly stabilize actin and its associated proteins and perhaps facilitates the progression of maturation and alters the structure of existing synapses at any stage of development.

\section{DISCUSSION}

We find that F-actin is required for the development and maintenance of young synapses. That young synapses use a supportive but readily modified foundation fits well with the idea that they are particularly plastic, being readily strengthened or weakened, formed or lost. Consistent with this, we find that increased activity can both reorganize and stabilize F-actin. Over time and as synapses incorporate additional proteins, maintenance of synapse ultrastructure and the localization of many synaptic proteins become independent of F-actin. These data show that the matu- ration of a CNS synapse is an extensive and regulatable process, similar to what has been described for the development of the neuromuscular junction.

\section{Actin anchors a young synapse}

Our data indicate that the basic elemental proteins required to assemble and retain a young hippocampal synapse are reliant on their links to the actin cytoskeleton. These basic elements include those molecules that cluster and anchor vesicles, the molecules that adhere presynaptic and postsynaptic membranes, and a nascent postsynaptic specialization. Our data do not rule out the possibility that remnant synaptic proteins or even some protosynapses remain after actin depolymerization in that newly formed contact sites have little in the way of recognizable morphological specializations (Ahmari et al., 2000). However, those synapses would probably not be functional in that the synaptic vesicle recycling that can be observed after actin depolymerization is insensitive to treatment with TeNT, a hallmark of nonsynaptic vesicle recycling (Verderio et al., 1999).

F-actin independence correlates well with the acquisition and retention of scaffolding proteins such as Bassoon in the presynaptic bouton and PSD-95 in the postsynaptic density, each of which contain multiple protein-protein interaction domains and are members of families of synaptically localized proteins (Garner et al., 2000). Many of the scaffolding proteins that have been identified can indirectly bind to actin, a result that is supported by our results showing that members of the PSD-95 family and Bassoon are at least partially anchored by F-actin at the synapse through $13 \mathrm{~d}$ in culture. However, most scaffolding proteins also bind transmembrane proteins or signaling proteins or to one another. Because synapse structure and many of the molecules in a more mature synapse are largely independent of both F-actin and microtubules (Allison et al., 1998, 2000; present data), such protein-protein interactions appear to be capable of generating a synaptic cytoskeleton that clusters and anchors receptors, adhesion molecules, and channels together with signaling molecules, creating a matrix strong enough to be isolated biochemically as a synaptic membrane fraction (Fig. 9) (Matus et al., 1975; Kelly and Cotman, 1978). Neuronal intermediate filaments may also provide additional structural support in that individual subunits have been found in dendritic spines and in PSDs and attached to an NR1 splice variant of the NMDA receptor (Benson et al., 1996; Ehlers et al., 1998; Walikonis et al., 2000), but there are no data that support the existence of typical intermediate filaments in the vicinity of synapses, suggesting that the subunits may be assembled into a novel structure.

\section{Actin as a target for synapse stabilization or elimination}

The end stages of synaptogenesis are characterized by synapse loss and rearrangement that occur in response to use-dependent pruning and refinement (Katz and Shatz, 1996) as well as to an initial overproduction of synapses in some regions (Bourgeois and Rakic, 1993; Sanes and Lichtman, 1999). In many areas synaptic competition is invoked in this process in which young synapses must be reinforced or they are eliminated (Cline et al., 1987; Katz and Shatz, 1996; Colman et al., 1997). Although neurotransmitter release appears to be required to retain synapses and dendritic spines once formed (McKinney et al., 1999; Verhage et al., 2000), the pattern and amount of neural activity appear to form the basis of synaptic competition at sites ranging from muscle innervation in rats (Thompson, 1983) to ocular dominance columns in the 
Table 2. Effects of actin depolymerization on PSD95- and Bassoon-labeled puncta

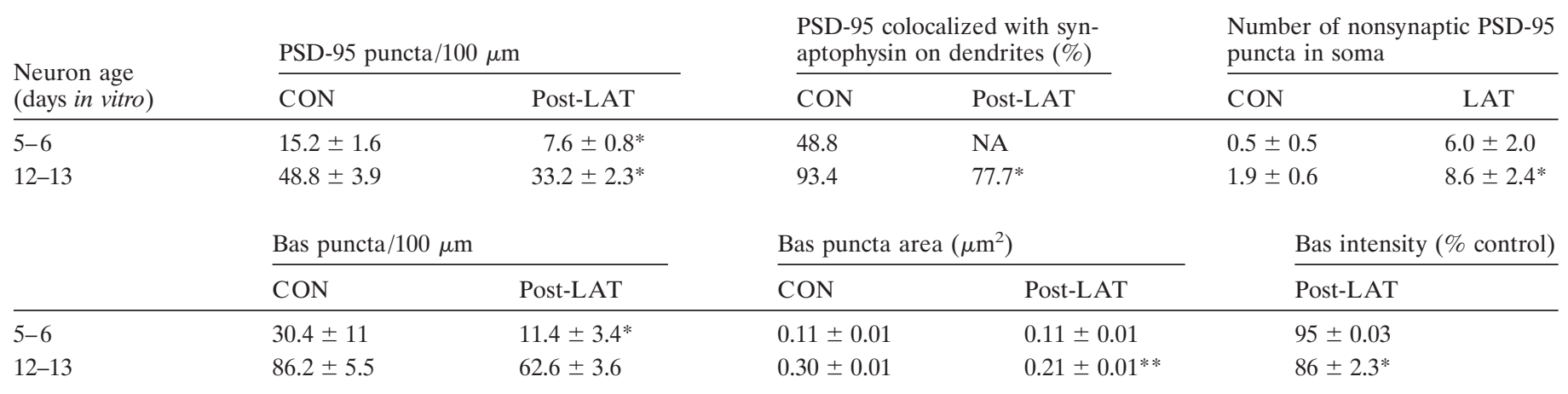

CON, Control; post-LAT, after latrunculin A; Bas, Bassoon. Numbers are mean \pm SEM.

$* p<0.002 ; * * p=0.019$.

visual cortex of cats and monkeys (Shatz and Stryker, 1978). Neurotrophins are suspected to be involved in translating activity into a morphological response (McAllister et al., 1999), but the molecular targets for such signals have been obscure. Our findings indicate that F-actin is a likely target for stimuli that would drive synapses toward stability or elimination in that it is essential but relatively easy to depolymerize in young neurons. There are ample signaling pathways that could then be invoked to reorganize the actin cytoskeleton (Hall, 1998).

That synapses progress through a relatively labile, actindependent stage also fits well with current models of long-term functional plasticity. Work from a number of different laboratories suggests that new synapse formation can occur within hours in response to various elements ranging from overall decreases in neural activity (Kirov and Harris, 1999) to awakening from hibernation (Popov and Bocharova, 1992) to the induction of long-lasting forms of long-term potentiation (Bailey and Chen, 1988; Engert and Bonhoeffer, 1999; Toni et al., 1999; Bozdagi et al., 2000). In fact, the maintenance phase of LTP in rodent hippocampus and of long-term facilitation in Aplysia appears to require actin assembly (Hatada et al., 2000; Krucker et al., 2000). Such mechanisms for rapid synapse proliferation must be balanced by synapse elimination, and an actin-dependent time window provides a means by which a neuron could generate and eliminate a transient population of synapses on a background of relatively stable synapses. In the more stable population, actin regulation may still induce changes in functional response properties (Morales et al., 2000), but this would not come at the expense of the synapse itself.

\section{Synaptic vesicles become differentially anchored over time}

It has long been suspected that the reserve pool of synaptic vesicles is tethered to the actin cytoskeleton via synapsin I (Hirokawa et al., 1989; Kelly, 1993; Pieribone et al., 1995; Kuromi and Kidokoro, 1998), but our data suggest that both releasable and reserve pools are initially tethered to F-actin. This early dependence may contribute to the delay in synaptogenesis observed in synapsin I-deficient mice (Chin et al., 1995). In intermediate-aged neurons, actin depolymerization reduces the size of most synaptophysin clusters, but vesicle recycling is largely unaffected, suggesting that the reserve pool remains tethered to F-actin, whereas the releasable pool has become alternatively anchored, perhaps to proteins composing the presynaptic cytomatrix or to the vesicle fusion machinery. In neurons $>18 \mathrm{~d}$ in culture, the size of the synaptophysin-labeled vesicle pool appears to be unaffected by actin depolymerization, suggesting that all vesicles may eventually be alternatively tethered to the synapse. These data fit well with most functional studies, the sum of which indicates that the process of synaptic vesicle release grows less sensitive to actin depolymerization over time (Betz and Henkel, 1994; Wang et al., 1996; Bernstein et al., 1998; Job and Lagnado, 1998; Kim and Lisman, 1999; Krucker et al., 2000). A noteworthy exception suggests that actin may continue to be involved in the regulation of vesicle release over short time periods (Morales et al., 2000).

\section{Adhesion at synapses}

In hippocampus, various adhesion molecules including L1, NCAM, and N-cadherin are expressed before the earliest stages of synaptogenesis (Persohn and Schachner, 1990; van den Pol and Kim, 1993; Benson and Tanaka, 1998), and cadherins are of particular interest in that $\mathrm{N}$-cadherin is one of the few molecules known to be clustered at young synaptic junctions both in hippocampal neurons grown in culture and at thalamocortical synapses in rat somatosensory cortex (Benson and Tanaka, 1998; Huntley and Benson, 1999). Similar cadherin recruitment and clustering at the lateral domains of epithelial cells is accompanied by actin-linked cell-cell adhesion that is essential for formation of adherens junctions (Nagafuchi and Takeichi, 1988; Fujimori and Takeichi, 1993; Rimm et al., 1995; Adams et al., 1996). That young synapses and their cadherin clusters are sensitive to actin depolymerization does not create a causal link between cadherin adhesion and the maintenance of nascent synapses, but it is an attractive correlation. Alternatively, recent work suggests that adhesion between neurexins and neuroligins may be a generic initiator of synapse formation (Scheiffele et al., 2000). No matter what the source or sources of adhesion, our data indicate that it must be anchored to actin.

So what adheres presynaptic and postsynaptic membranes at a mature synapse? In addition to cadherins, members of the integrin and Ig superfamilies, neurexins and neuroligins, proteoglycans, neuronal pentraxins, Ephs, and ephrins have all been localized to synapses (Persohn and Schachner, 1990; Ushkaryov et al., 1992; Einheber et al., 1996; Benson et al., 1998; Hsueh et al., 1998; Nishimura et al., 1998; Torres et al., 1998; Buchert et al., 1999; Ethell and Yamaguchi, 1999; O'Brien et al., 1999; Song et al., 1999). Of those that have been examined, most do not cluster at young synaptic sites (Persohn and Schachner, 1990; Benson et al., 1998; Ethell and Yamaguchi, 1999), but nearly all form discrete 

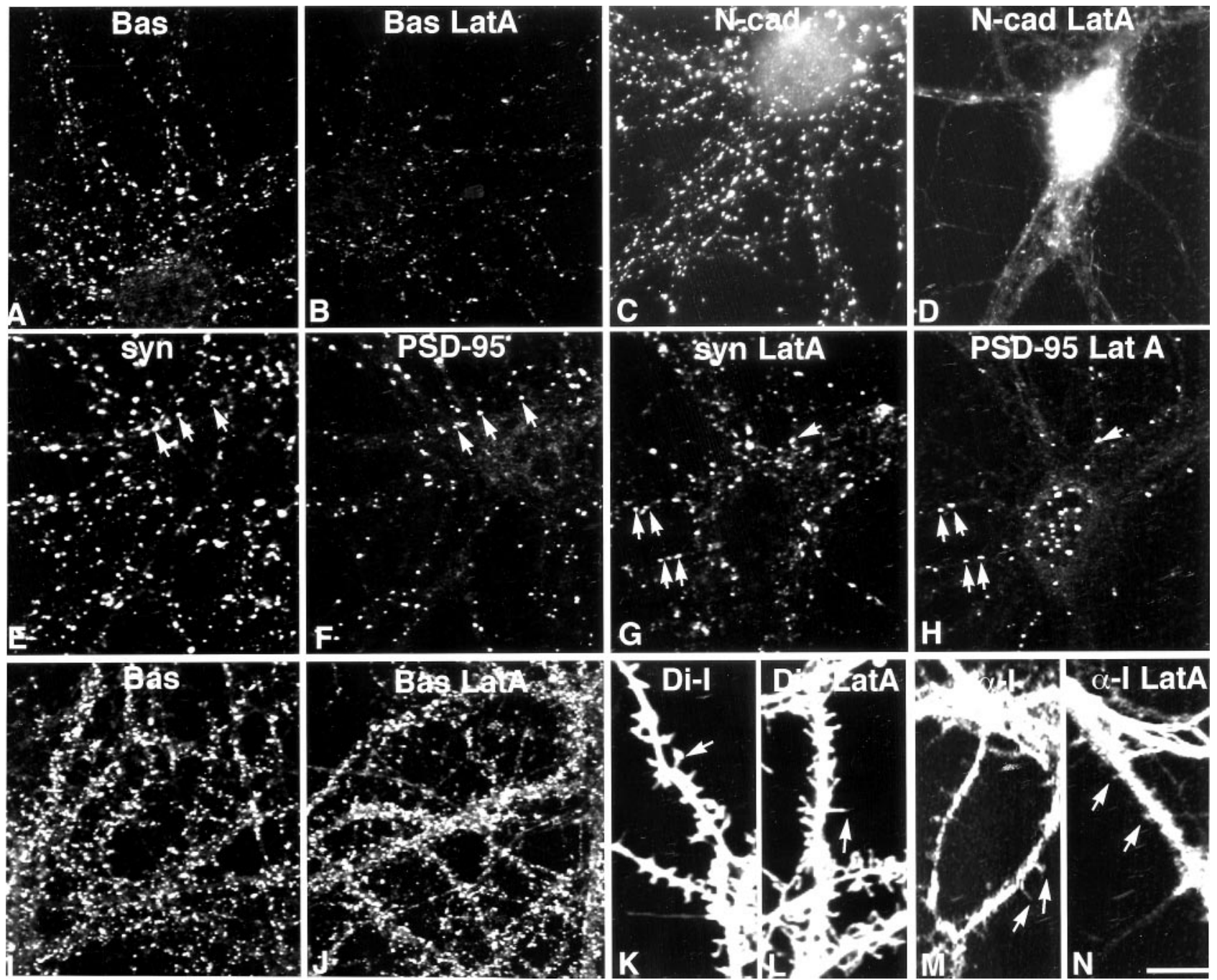

Figure 8. In 12-d-old neurons $(A-H)$, Bassoon-labeled clusters $(A, B a s)$ are diminished in size and number after latrunculin A treatment $(B, B a s$ Lat $A)$, but are still readily detected. $\mathrm{N}$-cadherin-labeled clusters $(C, N$-cad $)$ are lost after latrunculin A treatment $(D, N$-cad LatA), but a few tiny puncta remain $(D)$. In control neurons, PSD-95 labeling $(F)$ codistributes with a subpopulation of synaptophysin boutons $(E$, syn, arrows). After latrunculin A treatment $(G, H)$, many synaptic PSD-95 puncta are retained $(G, H$, arrows), but many PSD-95 puncta are nonsynaptic, which is particularly evident in the cell soma $(H)$. In 20-d-old neurons, latrunculin A treatment does not affect the distribution of Bassoon $(J)$ compared with untreated control neurons $(I)$. Di-I labeling reveals both spine-like and filopodia-like protrusions in control neurons $(K)$. After latrunculin A treatment, nearly all protrusions appear filopodia-like $(L)$. $\alpha$-internexin $(\alpha-I)$ labeling is concentrated in axons, but also appears in dendrites where it can be seen to invade protrusions $(M)$. After latrunculin A treatment, $\alpha$-internexin labeling remains at the base of dendritic protrusions $(N)$. Scale bar: $A-J, 20.2 \mu \mathrm{m} ; K-N, 11.3 \mu \mathrm{m}$.

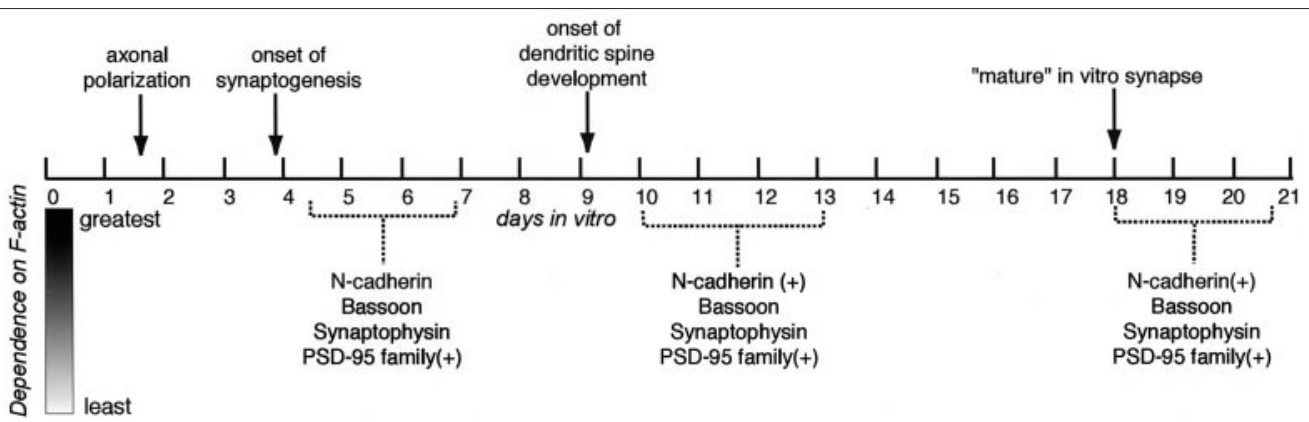

Figure 9. Juxtaposed against a time line summarizing major developmental events in cultured hippocampal neurons are synaptic proteins that are written with black, medium gray, or light gray to depict their dependence on F-actin for their synaptic localization (black = most dependent). Molecules restricted to excitatory synapses are indicated by $(+)$. 
clusters as neurons mature and often segregate to discrete synapse populations (Persohn and Schachner, 1990; Einheber et al., 1996; Benson and Tanaka, 1998; Nishimura et al., 1998; Buchert et al., 1999; Ethell and Yamaguchi, 1999; O'Brien et al., 1999; Song et al., 1999). That a multitude of adhesion proteins should eventually join synaptic membranes indicates that there is likely to be a certain level of redundancy, but also underscores the importance of maintaining a core synaptic structure. It also provides a means by which cell adhesion molecules and actin could orchestrate aspects of synapse plasticity (Benson et al., 2000) without necessarily endangering basic synaptic structure.

\section{REFERENCES}

Adams CL, Nelson WJ, Smith SJ (1996) Quantitative analysis of cadherin-catenin-actin reorganization during development of cell-cell adhesion. J Cell Biol 135:1899-1911.

Adam G, Matus A (1996) Role of actin in the organization of brain postsynaptic densities. Brain Res Mol Brain Res 43:246-250.

Ahmari SE, Buchanan J, Smith SJ (2000) Assembly of presynaptic active zones from cytoplasmic transport packets. Nat Neurosci 3:445-451.

Allison DW, Gelfand VI, Spector I, Craig AM (1998) Role of actin in anchoring postsynaptic receptors in cultured hippocampal neurons: differential attachment of NMDA versus AMPA receptors. J Neurosci 18:2423-2436.

Allison DW, Chervin AS, Gelfand VI, Craig AM (2000) Postsynaptic scaffolds of excitatory and inhibitory synapses in hippocampal neurons: maintenance of core components independent of actin filaments and microtubules. J Neurosci 20:4545-4554.

Apperson ML, Moon IS, Kennedy MB (1996) Characterization of densin-180, a new brain-specific synaptic protein of the $O$-sialoglycoprotein family. J Neurosci 16:6839-6852.

Bailey CH, Chen M (1988) Long-term memory in Aplysia modulates the total number of varicosities of single identified sensory neurons. Proc Natl Acad Sci USA 85:2373-2377.

Bartlett WP, Banker GA (1984) An electron microscopic study of the development of axons and dendrites by hippocampal neurons in culture II. Synaptic relationships. J Neurosci 4:1954-1965.

Benson DL, Cohen PA (1996) Activity-independent segregation of excitatory and inhibitory synaptic terminals in cultured hippocampal neurons. J Neurosci 16:6424-6432.

Benson DL, Tanaka H (1998) N-cadherin redistribution during synaptogenesis in hippocampal neurons. J Neurosci 18:6892-6904.

Benson DL, Mandell JW, Shaw G, Banker G (1996) Compartmentation of alpha-internexin and neurofilament triplet proteins in cultured hippocampal neurons. J Neurocytol 25:181-196.

Benson DL, Yoshihara Y, Mori K (1998) Polarized distribution and cell-type specific localization of telencephalin, an intercellular adhesion molecule. J Neurosci Res 52:43-53.

Benson DL, Schnapp LM, Shapiro L, Huntley GW (2000) Making memories stick: cell adhesion molecules in synaptic plasticity. Trends Cell Biol 10:512-526.

Bernstein BW, DeWit M, Bamburg JR (1998) Actin disassembles reversibly during electrically induced recycling of synaptic vesicles in cultured neurons. Brain Res Mol Brain Res 53:236-251.

Betz WJ, Henkel AW (1994) Okadaic acid disrupts clusters of synaptic vesicles in frog motor nerve terminals. J Cell Biol 124:843-854.

Bonfoco E, Leist M, Zhivotovsky B, Orrenius S, Lipton SA, Nicotera P (1996) Cytoskeletal breakdown and apoptosis elicited by NO donors in cerebellar granule cells require NMDA receptor activation. J Neurochem 67:2484-2493.

Bourgeois JP, Rakic P (1993) Changes of synaptic density in the primary visual cortex of the macaque monkey from fetal to adult stage. J Neurosci 13:2801-2820.

Bozdagi O, Shan W, Tanaka H, Benson DL, Huntley GW (2000) Increasing numbers of synaptic puncta during late-phase LTP: $\mathrm{N}$-cadherin is synthesized, recruited to synaptic sites and required for potentiation. Neuron 28:245-259.

Buchert M, Schneider S, Meskenaite V, Adams MT, Canaani E, Baechi T, Moelling K, Hovens CM (1999) The junction-associated protein AF-6 interacts and clusters with specific Eph receptor tyrosine kinases at specialized sites of cell-cell contact in the brain. J Cell Biol 144:361-371.

Chin LS, Li L, Ferreira A, Kosik KS, Greengard P (1995) Impairment of axonal development and of synaptogenesis in hippocampal neurons of synapsin I-deficient mice. Proc Natl Acad Sci USA 92:9230-9234.

Cline HT, Debski EA, Constantine-Paton M (1987) N-methyl-Daspartate receptor antagonist desegregates eye-specific stripes. Proc Natl Acad Sci USA 84:4342-4345.

Colman H, Nabekura J, Lichtman JW (1997) Alterations in synaptic strength preceding axon withdrawal. Science 275:356-361.
Dai Z, Peng HB (1996) Dynamics of synaptic vesicles in cultured spinal cord neurons in relationship to synaptogenesis. Mol Cell Neurosci 7:443-452.

Dunaevsky A, Connor EA (2000) F-actin is concentrated in nonrelease domains at frog neuromuscular junctions. J Neurosci 20:6007-6012.

Ehlers MD, Fung ET, O’Brien RJ, Huganir RL (1998) Splice variantspecific interaction of the NMDA receptor subunit NR1 with neuronal intermediate filaments. J Neurosci 18:720-730.

Einheber S, Schnapp LM, Salzer JL, Cappiello ZB, Milner TA (1996) Regional and ultrastructural distribution of the alpha 8 integrin subunit in developing and adult rat brain suggests a role in synaptic function. J Comp Neurol 370:105-134.

Engert F, Bonhoeffer T (1999) Dendritic spine changes associated with hippocampal long-term synaptic plasticity. Nature 399:66-70.

Ethell IM, Yamaguchi Y (1999) Cell surface heparan sulfate proteoglycan syndecan-2 induces the maturation of dendritic spines in rat hippocampal neurons. J Cell Biol 144:575-586.

Fannon AM, Colman DR (1996) A model for central synaptic junctional complex formation based on the differential adhesive specificities of the cadherins. Neuron 17:423-434.

Fenster SD, Chung WJ, Zhai R, Cases-Langhoff C, Voss B, Garner AM, Kaempf U, Kindler S, Gundelfinger ED, Garner CC (2000) Piccolo, a presynaptic zinc finger protein structurally related to bassoon. Neuron 25:203-214.

Fiala JC, Feinberg M, Popov V, Harris KM (1998) Synaptogenesis via dendritic filopodia in developing hippocampal area CA1. J Neurosci 18:8900-8911.

Fletcher TL, Cameron P, De Camilli P, Banker G (1991) The distribution of synapsin I and synaptophysin in hippocampal neurons developing in culture. J Neurosci 11:1617-1626.

Fowler VM (1997) Capping actin filament growth: tropomodulin in muscle and nonmuscle cells. Soc Gen Physiol Ser 52:79-89.

Friedman HV, Bresler T, Garner CC, Ziv NE (2000) Assembly of new individual excitatory synapses: time course and temporal order of synaptic molecule recruitment. Neuron 27:57-69.

Fujimori T, Takeichi M (1993) Disruption of epithelial cell-cell adhesion by exogenous expression of a mutated nonfunctional N-cadherin. Mol Biol Cell 4:37-47.

Furuyashiki T, Narumiya S, Bito H (1999) Activity-dependent relocation of actin visualized in synaptically connected hippocampal neurons. Soc Neurosci Abstr 25:185.6.

Garner CC, Nash J, Huganir RL (2000) PDZ domains in synapse assembly and signalling. Trends Cell Biol 10:274-280.

Goslin K, Banker G (1991) Rat hippocampal neurons in low density culture. In: Culturing nerve cells (Banker G, Goslin K, eds), pp 251282. Cambridge: MIT.

Goslin K, Birgbauer E, Banker G, Solomon F (1989) The role of cytoskeleton in organizing growth cones: a microfilament-associated growth cone component depends upon microtubules for its localization. J Cell Biol 109:1621-1631.

Hall A (1998) Rho GTPases and the actin cytoskeleton. Science 279:509-514.

Halpain S, Hipolito A, Saffer L (1998) Regulation of F-actin stability in dendritic spines by glutamate receptors and calcineurin. J Neurosci 18:9835-9844.

Hatada Y, Wu F, Sun ZY, Schacher S, Goldberg DJ (2000) Presynaptic morphological changes associated with long-term synaptic facilitation are triggered by actin polymerization at preexisting varicosities. J Neurosci 20:RC82(1-4)

Hirokawa N, Sobue K, Kanda K, Harada A, Yorifuji H (1989) The cytoskeletal architecture of the presynaptic terminal and molecular structure of synapsin 1. J Cell Biol 108:111-126.

Hiscock JJ, Murphy S, Willoughby JO (2000) Confocal microscopic estimation of GABAergic nerve terminals in the central nervous system. J Neurosci Methods 95:1-11.

Hsueh YP, Yang FC, Kharazia V, Naisbitt S, Cohen AR, Weinberg RJ, Sheng M (1998) Direct interaction of CASK/LIN-2 and syndecan heparan sulfate proteoglycan and their overlapping distribution in neuronal synapses. J Cell Biol 142:139-151.

Huntley GW, Benson DL (1999) N-cadherin at developing thalamocortical synapses provides an adhesion mechanism for the formation of somatotopically organized connections. J Comp Neurol 407:453-471.

Job C, Lagnado L (1998) Calcium and protein kinase C regulate the actin cytoskeleton in the synaptic terminal of retinal bipolar cells. J Cell Biol 143:1661-1672.

Katz LC, Shatz CJ (1996) Synaptic activity and the construction of cortical circuits. Science 274:1133-1138.

Kelly PT, Cotman CW (1978) Synaptic proteins. Characterization of tubulin and actin and identification of a distinct postsynaptic density polypeptide. J Cell Biol 79:173-183.

Kelly RB (1993) Storage and release of neurotransmitters. Cell/Neuron 72/10[Suppl]:43-53.

Kim CH, Lisman JE (1999) A role of actin filament in synaptic transmission and long-term potentiation. J Neurosci 19:4314-4324.

Kirov SA, Harris KM (1999) Dendrites are more spiny on mature hip- 
pocampal neurons when synapses are inactivated. Nat Neurosci 2:878-883.

Kraszewski K, Mundigl O, Daniell L, Verderio C, Matteoli M, De Camilli P (1995) Synaptic vesicle dynamics in living cultured hippocampal neurons visualized with CY3-conjugated antibodies directed against the lumenal domain of synaptotagmin. J Neurosci 15:4328-4342.

Krucker T, Siggins GR, Halpain S (2000) Dynamic actin filaments are required for stable long-term potentiation (LTP) in area CA1 of the hippocampus. Proc Natl Acad Sci USA 97:6856-6861.

Kuromi H, Kidokoro Y (1998) Two distinct pools of synaptic vesicles in single presynaptic boutons in a temperature-sensitive Drosophila mutant, shibire. Neuron 20:917-925.

Matus AI, Walters BB, Jones DH (1975) Junctional ultrastructure in isolated synaptic membranes. J Neurocytol 4:357-367.

McAllister AK, Stevens CF (2000) Nonsaturation of AMPA and NMDA receptors at hippocampal synapses. Proc Natl Acad Sci USA 97:6173-6178.

McAllister AK, Katz LC, Lo DC (1999) Neurotrophins and synaptic plasticity. Annu Rev Neurosci 22:295-318.

McKinney RA, Capogna M, Durr R, Gahwiler BH, Thompson SM (1999) Miniature synaptic events maintain dendritic spines via AMPA receptor activation. Nat Neurosci 2:44-49.

Morales M, Colicos MA, Goda Y (2000) Actin-dependent regulation of neurotransmitter release at central synapses. Neuron 27:539-550.

Muller BM, Kistner U, Veh RW, Cases-Langhoff C, Becker B, Gundelfinger ED, Garner CC (1995) Molecular characterization and spatial distribution of SAP97, a novel presynaptic protein homologous to SAP90 and the Drosophila discs-large tumor suppressor protein. J Neurosci 15:2354-2366.

Nagafuchi A, Takeichi M (1988) Cell binding function of E-cadherin is regulated by the cytoplasmic domain. EMBO J 7:3679-3684.

Naisbitt S, Kim E, Tu JC, Xiao B, Sala C, Valtschanoff J, Weinberg RJ, Worley PF, Sheng M (1999) Shank, a novel family of postsynaptic density proteins that binds to the NMDA receptor/PSD-95/GKAP complex and cortactin. Neuron 23:569-582.

Nishimura SL, Boylen KP, Einheber S, Milner TA, Ramos DM, Pytela R (1998) Synaptic and glial localization of the integrin alphavbeta8 in mouse and rat brain. Brain Res 791:271-282.

O’Brien RJ, Xu D, Petralia RS, Steward O, Huganir RL, Worley P (1999) Synaptic clustering of AMPA receptors by the extracellular immediateearly gene product Narp. Neuron 23:309-323.

Persohn E, Schachner M (1990) Immunohistological localization of the neural adhesion molecules L1 and N-CAM in the developing hippocampus of the mouse. J Neurocytol 19:807-819.

Peters A, Palay SL, Webster HD (1991) The fine structure of the nervous system. New York: Oxford UP.

Pieribone VA, Shupliakov O, Brodin L, Hilfiker-Rothenfluh S, Czernik AJ, Greengard P (1995) Distinct pools of synaptic vesicles in neurotransmitter release. Nature 375:493-497.

Popov VI, Bocharova LS (1992) Hibernation-induced structural changes in synaptic contacts between mossy fibres and hippocampal pyramidal neurons. Neuroscience 48:53-62.

Rao A, Kim E, Sheng M, Craig AM (1998) Heterogeneity in the molecular composition of excitatory postsynaptic sites during development of hippocampal neurons in culture. J Neurosci 18:1217-1229.

Rimm DL, Koslov ER, Kebriaei P, Cianci CD, Morrow JS (1995) Alpha1 (E)-catenin is an actin-binding and -bundling protein mediating the attachment of F-actin to the membrane adhesion complex. Proc Natl Acad Sci USA 92:8813-8817.

Ryan TA, Reuter H, Wendland B, Schweizer FE, Tsien RW, Smith SJ (1993) The kinetics of synaptic vesicle recycling measured at single presynaptic boutons. Neuron 11:713-724.

Sanes JR, Lichtman JW (1999) Development of the vertebrate neuromuscular junction. Annu Rev Neurosci 22:389-442.

Sans N, Petralia RS, Wang YX, Blahos II J, Hell JW, Wenthold RJ (2000) A developmental change in NMDA receptor-associated proteins at hippocampal synapses. J Neurosci 20:1260-1271.

Sattler R, Xiong Z, Lu WY, MacDonald JF, Tymianski M (2000) Dis- tinct roles of synaptic and extrasynaptic NMDA receptors in excitotoxicity. J Neurosci 20:22-33.

Scheiffele P, Fan J, Choih J, Fetter R, Serafini T (2000) Neuroligin expressed in nonneuronal cells triggers presynaptic development in contacting axons. Cell 101:657-669.

Schiavo G, Benfenati F, Poulain B, Rossetto O, Polverino de Laureto P, DasGupta BR, Montecucco C (1992) Tetanus and botulinum-B neurotoxins block neurotransmitter release by proteolytic cleavage of synaptobrevin. Nature 359:832-835.

Segal M (1983) Rat hippocampal neurons in culture: responses to electrical and chemical stimuli. J Neurophysiol 50:1249-1264.

Shatz CJ, Stryker MP (1978) Ocular dominance in layer IV of the cat's visual cortex and the effects of monocular deprivation. J Physiol (Lond) 281:267-283.

Song JY, Ichtchenko K, Sudhof TC, Brose N (1999) Neuroligin 1 is a postsynaptic cell-adhesion molecule of excitatory synapses. Proc Natl Acad Sci USA 96:1100-1105.

Tanaka H, Shan W-S, Phillips G, Arndt K, Bozdagi O, Shapiro L, Huntley GW, Benson DL, Colman DR (2000) Molecular modification of $\mathrm{N}$-cadherin in response to synaptic activity. Neuron 28:93-107.

Thompson W (1983) Synapse elimination in neonatal rat muscle is sensitive to pattern of muscle use. Nature 302:614-616.

tom Dieck S, Sanmarti-Vila L, Langnaese K, Richter K, Kindler S, Soyke A, Wex H, Smalla KH, Kampf U, Franzer JT, Stumm M, Garner CC, Gundelfinger ED (1998) Bassoon, a novel zinc-finger CAG/glutaminerepeat protein selectively localized at the active zone of presynaptic nerve terminals. J Cell Biol 142:499-509.

Toni N, Buchs PA, Nikonenko I, Bron CR, Muller D (1999) LTP promotes formation of multiple spine synapses between a single axon terminal and a dendrite. Nature 402:421-425.

Torres R, Firestein BL, Dong H, Staudinger J, Olson EN, Huganir RL, Bredt DS, Gale NW, Yancopoulos GD (1998) PDZ proteins bind, cluster, and synaptically colocalize with Eph receptors and their ephrin ligands. Neuron 21:1453-1463.

Ushkaryov YA, Petrenko AG, Geppert M, Sudhof TC (1992) Neurexins: synaptic cell surface proteins related to the alpha-latrotoxin receptor and laminin. Science 257:50-56.

van den Pol AN, Kim WT (1993) NILE/L1 and NCAM-polysialic acid expression on growing axons of isolated neurons. J Comp Neurol 332:237-257.

Verderio C, Coco S, Bacci A, Rossetto O, De Camilli P, Montecucco C, Matteoli M (1999) Tetanus toxin blocks the exocytosis of synaptic vesicles clustered at synapses but not of synaptic vesicles in isolated axons. J Neurosci 19:6723-6732.

Verhage M, Maia AS, Plomp JJ, Brussaard AB, Heeroma JH, Vermeer H, Toonen RF, Hammer RE, van den Berg TK, Missler M, Geuze HJ, Sudhof TC (2000) Synaptic assembly of the brain in the absence of neurotransmitter secretion. Science 287:864-869.

Walikonis RS, Jensen ON, Mann M, Provance Jr DW, Mercer JA, Kennedy MB (2000) Identification of proteins in the postsynaptic density fraction by mass spectrometry. J Neurosci 20:4069-4080.

Wang XH, Zheng JQ, Poo MM (1996) Effects of cytochalasin treatment on short-term synaptic plasticity at developing neuromuscular junctions in frogs. J Physiol (Lond) 491:187-195.

Wong WT, Faulkner-Jones BE, Sanes JR, Wong RO (2000) Rapid dendritic remodeling in the developing retina: dependence on neurotransmission and reciprocal regulation by Rac and Rho. J Neurosci 20:5024-5036.

Zakharenko S, Chang S, O’Donoghue M, Popov SV (1999) Neurotransmitter secretion along growing nerve processes: comparison with synaptic vesicle exocytosis [Erratum (1999) 144(4)]. J Cell Biol 144:507-518

Zhai R, Olias G, Chung WJ, Lester RA, tom Dieck S, Langnaese K, Kreutz MR, Kindler S, Gundelfinger ED, Garner CC (2000) Temporal appearance of the presynaptic cytomatrix protein bassoon during synaptogenesis. Mol Cell Neurosci 15:417-428.

Zhang W, Benson DL (2000) Development and molecular organization of dendritic spines and their synapses. Hippocampus 10:512-526. 